\title{
FRAMEWORK PARA CLASSIFICAÇÃO DE GRÃOS
}

\author{
Emili Everz ${ }^{1}$, Bruna Neves Machado ${ }^{2}$ e Maria Salete Marcon Gomes Vaz ${ }^{3}$ \\ Universidade Estadual de Ponta Grossa, Brasil \\ ${ }^{I}$ Aluna de Iniciação Científica \\ ${ }^{2}$ Mestranda \\ ${ }^{3}$ Dr ${ }^{a}$, Professora Associada do Programa de Pós-Graduação em Computação Aplicada
}

\begin{abstract}
RESUMO
Atualmente, a tecnologia se mostra como ferramenta facilitadora para trabalho em diversas áreas, entre elas destacamos que pode ser utilizada para auxílio na classificação de grãos. No Brasil, é utilizada minimamente e utilizando o método manual para a separação dos grãos. Objetiva-se utilizar um framework para padrão de metadados com ênfase na classificação de grãos para facilitar o trabalho dos classificadores de grãos, de maneira a apresentar como a tecnologia pode trazer benefícios a diversos setores. Havendo a necessidade de todos os classificadores, mesmo os que não têm grande contato com a tecnologia, serem capazes de operar o framework. É indiscutível que este se apresente de maneira simples. Para tanto, em seu desenvolvimento o foco foi criar uma interface simples e amigável ao usuário. Ao inserir o framework em campo, este fará com que o trabalho dos classificadores se torne mais rápido e eficiente, diminuindo a possibilidade de erro, o que permite concluir a necessidade de cada vez mais a tecnologia estar presente nas mais diversas áreas de atuação de toda a sociedade.
\end{abstract}

\section{PALAVRAS-CHAVE}

Framework, Classificação de Grãos, Agricultura, Tecnologia

\section{INTRODUÇÃO}

O Brasil possui uma grande produção agrícola, principalmente, voltada à exportação (SILVA JUNIOR, 2019). A grande produção nacional de grãos faz com que o número de comercializações seja elevado, para cada tipo de grãos, seja para consumo interno ou exportação, faz com que os governos federais, estaduais e municipais, juntamente com o MAPA - Ministério de Agricultura, Pecuária e Abastecimento - determinem regras a serem seguidas. Uma delas determina a classificação dos grãos destinados ao consumo humano, seja in natura ou processados. Cada grão deve seguir uma norma de classificação diferente, segundo normas e portarias.

Os Metadados, dados sobre dados, ou seja, é uma forma de descrever dados, facilitando assim a organização das informações (MANOUSELIS et al., 2010; NISO, 2017; STEINACKER; GHAVAM; STEINMETZ, 2001) para classificação. Já o Padrão de Metadados é uma forma de organizar os metadados para que possam ser utilizados em diferentes plataformas, sistemas e possam interagir com meio externo. Já foi possível, com os estudos relacionados à classificação de grãos, elaborar metadados para melhoria do gerenciamento de informações relacionadas aos grãos.

Através desses metadados será desenvolvido um framework para realizar o gerenciamento das informações relacionadas aos grãos. $\mathrm{O}$ framework deve, acima de qualquer coisa, apresentar uma interface simples para que qualquer usuário seja capaz de utilizá-lo. Desde o principio a ideia da criação de um framework para padrão de metadados surgiu pela necessidade de facilitar a vida do produtor rural e seus classificadores, que são, então, nossos usuários alvos.

Outro ponto extremamente importante de ser ressaltado é a utilização de tabelas impressas e laudos de classificação para poder garantir precisão na sua classificação e nos dados passados adiante. $\mathrm{O}$ framework pode garantir que o usuário poderá ter todas essas informações em um único dispositivo e compartilhá-la com outros dispositivos sem a necessidade de acúmulo de papel. 
Para garantir o funcionamento deste framework foi necessário criar um padrão de metadados para classificação de grãos, o qual apresenta as peculiaridades e semelhanças entre os grãos, onde pode ser visto que os grãos possuem especificidades em relação à nomenclatura, porém os defeitos apresentados são os mesmos, o que, para o computador pode representar o mesmo dado e simplesmente ser apresentado ao usuário com sue nome específico.

A grande contribuição desse desenvolvimento é apresentada pelo fato da tecnologia ser uma ferramenta facilitadora de todos os trabalhos, das mais diversas áreas, esta vem para garantir maior agilidade, eficiência e diminuição de erros, haja vista que a "máquina humana" é imperfeita enquanto os erros de um computador são previsíveis e podem ser tratados a modo de ser um trabalho completo e com quase $100 \%$ de garantia de acertos.

\section{REFERENCIAL TEÓRICO}

Metadados são definidos, basicamente, como dados sobre outros dados ou informação sobre informações, sendo uma informação estruturada que tem como objetivo identificar, descrever, explicar, localizar, facilitar a recuperação e o uso de dados (MANOUSELIS et al., 2010; NISO, 2017; STEINACKER; GHAVAM; STEINMETZ, 2001). Com a utilização de metadados é possível obter informações rapidamente através de um conjunto de dados, com o objetivo de auxiliar na tomada de decisões.

Padrões de metadados têm como objetivo (NASCIMENTO, 2008):

I. Auxiliar na recuperação de informações e dados;

II. Estabelecer comunicação consistente entre banco de dados;

III. Garantir o registro de informações relevantes;

IV. Facilitar o uso e compartilhamento de informações e conhecimentos, para humanos e máquinas;

V. Auxiliar a troca de informações entre diferentes sistemas e banco de dados.

O framework para a classificação de grãos tem como objetivo armazenar, gerir, realizar buscas e garantir a qualidade do produto que será importado, exportado ou comercializado. A Lei no 9.972, de 25 de maio de 2000, institui a classificação de todos os produtos vegetais destinados diretamente à alimentação humana, sendo o MAPA responsável por determinar os padrões de classificação por meio de normativas ou portarias (BRASIL, 2000).

Para eficiência do trabalho do framework, ele se baseia no padrão de metadados para classificação de grãos (EVERZ et al., 2019), o padrão (figura 1 - EVERZ et al., 2019) sustenta as características em comum apresentadas pelos grãos mesmo que durante a classificação cada uma de suas tabelas específicas apresente um nome específico. Sabendo que o framework se baseia no padrão de metadados para classificação de grãos, uma preocupação é o fato dos dados da empresa jamais poderem ser mais flexíveis que os dados do MAPA, sendo que esses são os mínimos exigidos para que os grãos possam ser comercializados, o framework se preocupa em não permitir que a empresa entre com dados mais flexíveis, pois isto faz com que os grãos não possam ser comercializados e a empresa perca uma carga de grãos, além do tempo gasto na classificação e na entrega do produto.

Um comando condicional pode fazer o framework bloquear a entrada de padrões mais flexíveis, mas ainda resta o fato de que este framework deve ter uma interface software - máquina simples, para que os usuários que não tem tanta afinidade com o ramo tecnológico possam utilizar desta mesma aparelhagem sem muita dificuldade, pois o objetivo deste mesmo padrão efetivado por meio de um framework é fazer com que o trabalho das pessoas seja facilitado, sabendo que muitas pessoas prefeririam manter a classificação da maneira que está sendo feita a terem que trabalhar com uma ferramenta de difícil manuseio. O padrão representa o que seria uma interface simples, onde qualquer usuário consegue seguir seu caminho, como se este fosse um "labirinto", no qual cada usuário deve seguir um caminho, ser sair das linhas indo a partir do que se tem até onde se quer chegar como objetivo final.

Além disso, um ponto que sustenta a necessidade deste framework é a carência de preservação do meio ambiente, e como, atualmente, o classificador depende de tabelas de classificação (tabela 01- MAPA) e laudos de classificação (figura 2 - MAPA) impressos. Suponhamos a necessidade de uma folha para cada tabela, considerando que cada grão pode possuir até três tabelas, uma para cada uso, e cada classificador possua todas essas tabelas, seriam muitas folhas gastas. O framework pode garantir que o usuário poderá ter todas essas 
informações em um único dispositivo e compartilhá-la com outros dispositivos sem a necessidade de acúmulo de papel.

Na ideia de trazer uma interface amigável ao usuário, a criação de uma aba inicial (figura 3), aba de escolha de segmento de dados (figura 4) e aba para processo de entrada de dados (figura 5) feitas da maneira mais simples e, portanto, mais compreensível torna o framework acessível a todos. Vale salientar que estas são apenas as principais abas de seu funcionamento, sendo que o framework completo se desdobra em mais opções.

\section{RESULTADOS E DISCUSSÃO}

Para que os usuários tenham facilidade na utilização do padrão de classificação de grãos, foi elaborado um diagrama (Figura 1) que descreve a maneira que a classificação de grão deve ser feita.

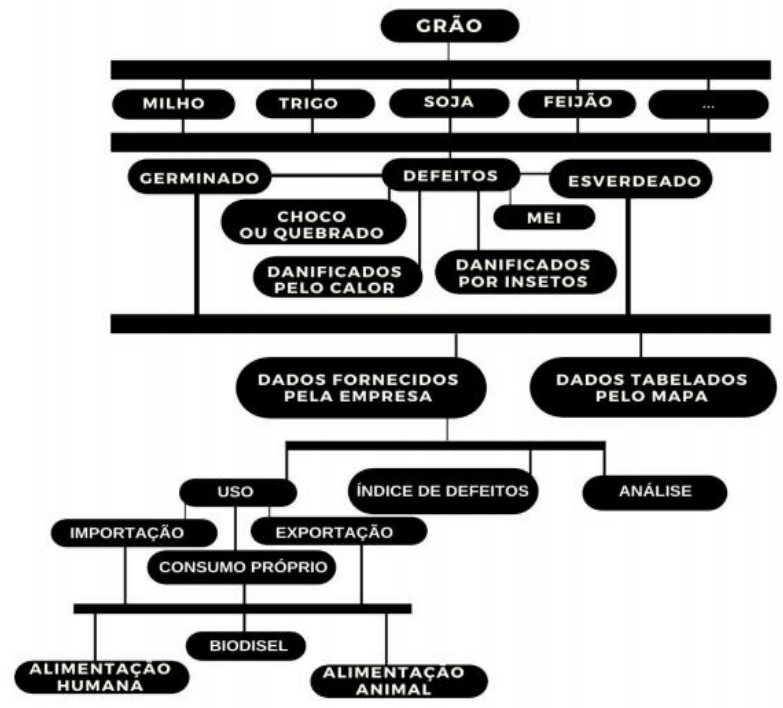

Figura 1. Padrão de Metadados para Classificação de Grãos

Para a classificação de um determinado grão, deve decidir quais normas serão utilizadas: Normas pré-definidas pelo MAPA ou, normas mais rígidas. As normas mais rígidas faz com que o padrão de qualidade do produto final seja maior, considerando que poderá escolher ter uma rigidez maior em relação à quantidade de defeitos aceitos ao fim do processo.

Para a classificação, por exemplo, do grão de milho, com aceitação de $0 \%$ de grãos carunchados, o framework aceitaria a entrada, supondo que para o milho ser classificado pelo MAPA é até 3\% de grãos carunchados para ser classificado de acordo com um tipo, mas se a aceitação fosse de $6 \%$ de grãos carunchados, o framework deve baixar automaticamente para as normas aceitas pelo MAPA, pois este é o valor mínimo necessário para que os grãos possam ser utilizados para algum fim, caso contrário os grãos estarão avariados demais para qualquer uso.

Uma nova área aparecerá para o usuário, pedindo que ele apresente o peso total de grãos que estejam sendo classificados e a pesagem de cada defeito encontrado para que o framework possa calcular e informar-lhe ao findar do processo em que tipo o grão se enquadra e, para quais finalidades ele pode ser utilizado ou, se deve para por reprocessamento para que possa ser classificado novamente com a possibilidade de resultado positivo.

Tabela 1. Limites máximos de tolerância a defeitos do milho expressos em percentual (\%)

\begin{tabular}{|c|c|c|c|c|c|}
\hline \multirow{2}{*}{ Enquadramento } & \multicolumn{2}{|c|}{ Grăos avariados } & \multirow{2}{*}{$\begin{array}{l}\text { Grấos } \\
\text { quebrados }\end{array}$} & \multirow{2}{*}{$\begin{array}{l}\text { Matérias estranhas } \\
\text { e impurezas }\end{array}$} & \multirow{2}{*}{ Carunchados } \\
\hline & \% Ardidos & Total & & & \\
\hline Tipo 1 & 1 & 6 & 3 & 1 & 2 \\
\hline $\operatorname{Tipo} 2$ & 2 & 10 & 4 & 1,5 & 3 \\
\hline Tipo 3 & 3 & 15 & 5 & 2 & 4 \\
\hline a de $T i s$ & 5 & 20 & zior que 5 & Maior que 2 & 8 \\
\hline
\end{tabular}


A Tabela 1 ilustra os índices de defeitos após a classificação dos grãos, para que o grão possa ser tipado. Esta tabela é o ponto de referência para o preenchimento do laudo de classificação.

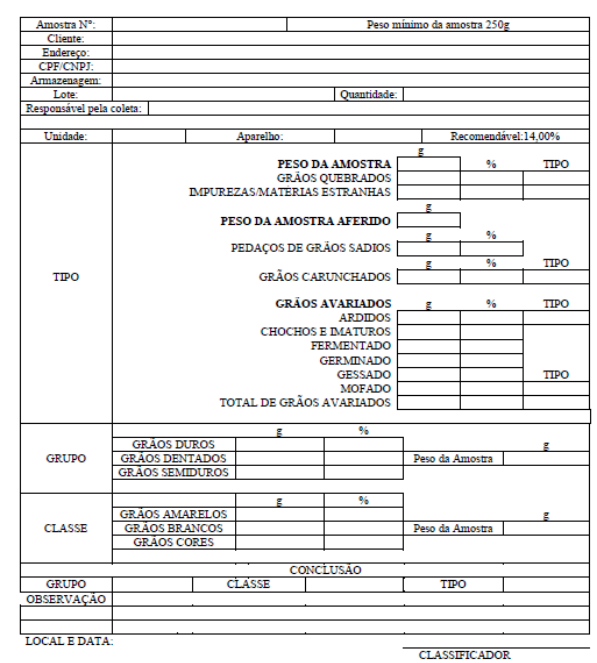

Figura 2. Laudo de classificação do milho

Quando se compram lotes de grãos, um classificador contratado pelo comprador vai até o local de embarque, acompanha o carregamento, coleta a amostra, classifica os grãos e emite um Laudo Interno de Classificação, como mostra a Figura 2.

Para dar início a classificação, deve-se escolher o tipo de grão que será classificado. A Figura 3, ilustra os diferentes tipos de grãos a serem escolhidos pelo classificador.

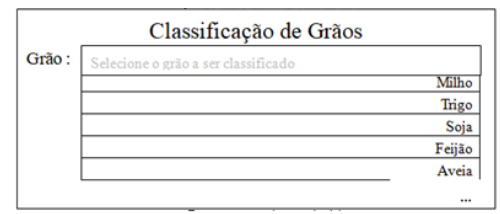

Figura 3. Aba inicial do framework

O laudo final que será apresentado pelo framework conterá as nomenclaturas específicas deste grão, pois como já foi citado os defeitos são muito semelhantes em todos os grãos, diferenciando-se basicamente pela nomenclatura.

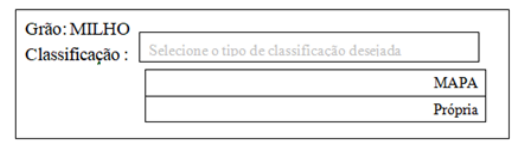

Figura 4. Aba para escolha de segmento de dados

A Figura 4 ilustra duas opções para a classificação: A do MAPA ou o próprio padrão definido pelo usuário, devendo estes serem mais rigorosos que os do MAPA, pois do contrário o framework irá substituí-los automaticamente pelos padrões do MAPA.

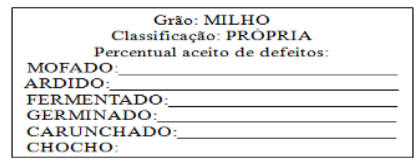

Figura 5. Aba para processo de entrada de dados

Considerando que o usuário tenha escolhido fazer uma classificação com índices próprios, o framework irá apresentar esta aba a ser preenchida com os valores escolhidos pelo usuário, a não ser que estejam mais flexíveis que os do MAPA, neste caso os valores serão substituídos pelos do MAPA. 


\section{CONCLUSÕES E PERSPECTIVAS DE PESQUISAS FUTURAS}

Conhecendo a necessidade de conservação do meio ambiente e o fato das áreas rurais nem sempre terem acesso à internet, um framework off-line criado para ajudar os classificadores em seu trabalho, sem a necessidade do uso de tabelas impressas e entradas em sites do ministério, diminuindo assim a utilização de papéis e facilitando o trabalho de produtores sem acesso à internet.

Porém, devemos reconhecer as limitações deste projeto, dado o fato de que alguns produtores rurais não possuem acesso a computadores para poderem, desta maneira, estabelecer o uso do framework em seu dia-a-dia, porém este ainda é útil para a maioria dos classificadores, pois a cada dia vemos que as pessoas estão tendo mais recursos tecnológicos, por mais que isto não valha para todos.

Como perspectivas de pesquisas futuras, sugere-se a utilização do framework de classificação de grãos em uma esteira classificadora, com um sensor de captura e comparação de imagens, automatizando e facilitando o processo de inserção para o usuário.

\section{AGRADECIMENTOS}

Agradeço a minha orientadora Maria Salete Marcon Gomes Vaz pelo suporte no pouco tempo que lhe coube, pelas suas correções, incentivos e por ter confiado em minha capacidade. Agradeço também a meu grupo de pesquisa e a todos que direta ou indiretamente me auxiliaram durante a pesquisa.

Agradeço a Fundação Araucária pela cessão de uma bolsa de auxílio à pesquisa que foi muito importante durante o projeto.

\section{REFERÊNCIAS}

Brasil. Câmara dos Deputados. LEI No 9.972, DE 25 DE MAIO DE 2000, Márcio Fortes de Almeida.

Everz, Emili et al. Validação do Padrão de Metadados para Classificação de Grãos. In: EAIC, 28., 2019, Ponta Grossa. Anais [...] . Ponta Grossa: Eaic, 2019. p. 1-4.

Manouselis, N. et al. Metadata interoperability in agricultural learning repositories: An analysis. Computers and Electronics in Agriculture. v. 70, n. 2, p. 302-320, ISSN 0168-1699. 2010.

Nascimento, L. U. Um Padrão de Metadados para Indexação e Recuperação de Objetos Multimídia. 2008. Dissertação (Mestrado em Informática). Universidade Federal do Paraná, Curitiba, 2008.

NISO, National Information Standards Organization. UNDERSTANDING METADATA WHAT IS METADATA, AND WHAT IS IT FOR? Disponível em: <http://www.niso.org>. Acesso em: 15 out. 2017.

Silva Junior, João Martins da. Agricultura no Brasil atual. 2019. Disponível em: https://www.sucessonocampo.com.br/artigos/agricultura-no-brasil-atual/. Acesso em: 03 set. 2019 